\title{
ENVIRONMENTAL AND HORMONAL CONTROL OF TURION GERMINATION IN MYRIOPHYLLUM VERTICILLATUM ${ }^{1}$
}

\author{
JAMES A. WEBER ${ }^{2}$ AND LARRY D. NoODÉN \\ Botany Department, University of Michigan, Ann Arbor 48109
}

A B S T R A C T

Germination, or outgrowth, of Myriophyllum verticillatum turions involves a series of visible changes starting with reflexing of leaves followed by extension and curving of the axis, and then by root formation. Before abscission, turions grow out in response to long days ( $16 \mathrm{hr})$ but not short days $(8 \mathrm{hr})$. After abscission, turions show maximal dormancy which can be fully broken by a cold treatment $(4 \mathrm{C})$. Turions are heterogeneous in degree of dormancy and ability to respond to less complete dormancy-breaking treatments, e.g., long days at $20 \mathrm{C}$. Cytokinins $\left(10^{-6} \mathrm{M}\right)$ break dormancy of non-cold-treated turions, whereas gibberellic acid $\left(\mathrm{GA}_{3}\right)$ is ineffective except at high concentrations $\left(10^{-3} \mathrm{M}\right)$. Continuous treatment with cytokinins causes abnormal development after germination. $\mathrm{GA}_{3}$, on the other hand, induces apparently normal development even at high concentration. Indoleacetic acid (IAA) induces outgrowth only at high concentrations $\left(10^{-3}-10^{-4} \mathrm{M}\right)$, but these concentrations also produce abnormal development. Abscisic acid (ABA, 10 $0^{-5} \mathrm{M}$ ) retards outgrowth of cold-treated turions and can completely suppress it in non-cold-treated turions. The activity of ABA-like substances in turions remains about the same before and during germination, whereas other (unidentified) acidic inhibitors decrease markedly. The cytokinin activity changes in a complex pattern.

THE ENVIRONMENTAL and hormonal control of dormancy and germination, or outgrowth, of turions have been studied in only a few species. These specialized buds of vascular hydrophytes are of interest, because they can be very important in propagation as well as overwintering of the plants (Weber, 1972).

Temperature and light have been found to affect the germination of some turions. For example, turions of some clones of Spirodela polyrhiza (L.) Schleiden require cold-treatments for germination, but other clones do not (Jacobs, 1947; Perry, 1968). Hydrocharis morsus-ranae L. turions require either a cold $(0-4 \mathrm{C})$ or a warm (greater than $40 \mathrm{C}$ ) treatment for germination (Vegis, 1932; 1955). Light has been shown to stimulate germination of turions of $H$. morsusrance (Terras, 1900).

Hormonal control of turion germination appears to be similar to that found in other buds. Kummerow (1958) and Lacor (1969), who studied $H$. morsus-ranae and $S$. polyrhiza, respectively, found that kinetin would promote turion germination, but that indoleacetic acid (IAA) antagonized

\footnotetext{
${ }^{1}$ Received for publication 28 July 1975.

Present address: Biological Station, University of Michigan, Ann Arbor, 48109.

This publication represents a portion of a dissertation presented to the $\mathbf{H}$. H. Rackham School of Graduate studies at The University of Michigan in partial fulfillment of the requirements for the degree of Doctor of Philosophy (J. A. W.). We wish to thank the HoffmanLaRoche Co. for the gift of $100 \mathrm{mg}$ of $\pm \mathrm{ABA}$ and the Amchem Products, Inc. for providing the Ethephon used in this study.
}

this action in $H$. morsus-ranae. Gibberellins were shown to promote turion germination in $S$. polyrhiza (Perry, 1968; Lacor, 1969). Pieterse, Bhalla, and Sabharwal (1971) found a lower level of gibberellin activity in turions than in actively growing plants of Wolffiella floridana (J. D. Smith) Thompson.

In order to extend our knowledge of the control of turion development and germination, a broad study of the turions of Myriophyllum verticillatum L., a submerged aquatic vascular plant, was undertaken. In this species, turions are distinct from normal vegetative buds; they abscise from the parent plant at maturity and are important in propagation and overwintering (Weber and Noodén, 1974a). Data on the environmental and hormonal control of dormancy and germination of $M$. verticillatum turions will be presented. Some of these data have been presented in other reports (Weber and Noodén, 1972, 1974b).

MATERIALS AND METHODS-Myriophyllum verticillatum turions were collected periodically during the fall and winter from local lakes and prepared for culture or extraction as described earlier (Weber and Noodén, 1976). Attached turions were collected from late September through October (Weber and Noodén, 1974a). Abscised, dormant turions were collected from late October through early November before the lake temperature dropped to $10 \mathrm{C}$. Some turions were also collected in the winter when ice covered the lake. Since it was not practical to produce large quantities of turions in growth chambers, or even in 
TABLE 1. The effect of photoperiod on elongation, degree of leaf reflexing, and root development of attached turions ${ }^{\text {it }}$

\begin{tabular}{|c|c|c|c|c|c|}
\hline \multirow[b]{2}{*}{ Treatment } & \multirow{2}{*}{$\begin{array}{l}\text { Time } \\
\text { (days) }\end{array}$} & \multicolumn{2}{|c|}{ Length } & \multirow{2}{*}{$\begin{array}{l}\text { Degree of } \\
\text { reflexing }\end{array}$} & \multirow{2}{*}{$\begin{array}{l}\text { No. of plants } \\
\text { with roots }\end{array}$} \\
\hline & & $(\mathrm{mm})^{\prime \prime}$ & $(\%)^{\mathrm{c}}$ & & \\
\hline $\mathrm{SD}$ & 0 & $28.7 \pm 6.0$ & - & 1 & 0 \\
\hline \multirow[t]{4}{*}{$15 \mathrm{C}$} & 9 & $29.7 \pm 6.0$ & 0 & 3 & 1 \\
\hline & 21 & $28.7 \pm 5.9$ & -3.4 & 3 & 1 \\
\hline & 29 & $29.8 \pm 6.3$ & 0.3 & 3 & 1 \\
\hline & 36 & $30.5 \pm 6.3$ & 2.7 & 3 & 1 \\
\hline LD & 0 & $34.3 \pm 6.6$ & - & 1 & 0 \\
\hline \multirow[t]{4}{*}{$15 \mathrm{C}$} & 9 & $35.0 \pm 7.9$ & 2.0 & 3 & 0 \\
\hline & 21 & $36.0 \pm 11.6$ & 5.0 & 3 & 4 \\
\hline & 29 & $40.3 \pm 16.3$ & 17.5 & 3 & 6 \\
\hline & 36 & $48.0 \pm 20.4$ & 39.9 & 4 & 6 \\
\hline
\end{tabular}

"Six turions per treatment.

"Average length of turions \pm standard deviation.

" Percent change from initial length.

d See Fig 1 for explanation.

greenhouses, we were dependent upon field-grown material, which was of limited availability.

Except where noted, all experiments on germination were conducted in growth chambers as described in another paper (Weber and Noodén, 1976). Experiments were carried out with distilled or tap water plus additives in 250-ml Erlenmeyer flasks ( 3 turions/flask); the solutions were changed every 7-10 days. Three to 6 turions were used in each experiment. Growth regulators were applied at $10^{-6}$ and $10^{-5} \mathrm{M}$, unless otherwise noted, and the levels in the treatment solutions were monitored by bioassay during the experiments. Gibberellic acid $\left(\mathrm{GA}_{3}\right)$ and benzyladenine (BA) activities were undiminished between the changes of solution; however, abscisic acid (ABA) and indoleacetic acid (IAA) activity declined about one order of magnitude in 7-10 days.

The effect of ethylene was tested by treating turions with $10^{-4} \mathrm{M}$ Ethephon (2-chloroethylphosphonic acid) in flasks which were tightly stoppered; these solutions plus the controls were changed twice a week.

Throughout the experiments, the turions were checked for qualitative and quantitative changes. Elongation was measured to the nearest $\mathrm{mm}$. The results are expressed as average length \pm standard deviation and, to facilitate comparison of the separate treatments, as the percent increase over initial length of the turions in each treatment.

TABLE 2. Effect of temperature and photoperiod on the elongation, leaf reflexing, and root developnent of abscised, dormant turions

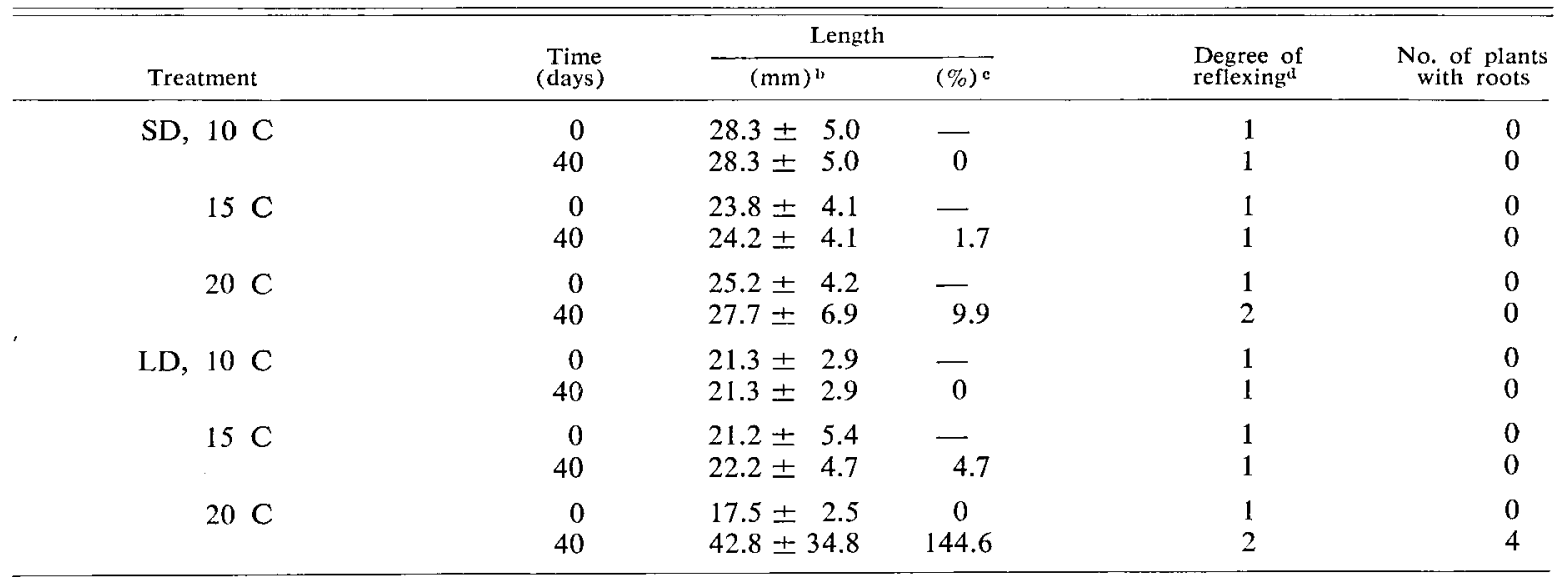

"Six turions per treatment.

b. c, "See footnotes for Table 1. 
TABLE 3. Effect of photoperiod on the elongation, degree of leaf reflexing, and root development of abscised, dormant turions which were cold-treated

\begin{tabular}{|c|c|c|c|c|c|}
\hline \multirow[b]{2}{*}{ Treatment } & \multirow{2}{*}{$\begin{array}{l}\text { Time } \\
\text { (days) }\end{array}$} & \multicolumn{2}{|c|}{ Length } & \multirow{2}{*}{$\begin{array}{l}\text { Degree of } \\
\text { reflexingd }\end{array}$} & \multirow{2}{*}{$\begin{array}{l}\text { No. of plants } \\
\text { with roots }\end{array}$} \\
\hline & & $(\mathrm{mm})^{\mathrm{b}}$ & $(\%)^{c}$ & & \\
\hline $\mathrm{SD}, 15 \mathrm{C}$ & $\begin{array}{r}0 \\
7 \\
14 \\
21 \\
28\end{array}$ & $\begin{array}{l}33.0 \pm 7.0 \\
35.7 \pm 9.5 \\
43.7 \pm 15.2 \\
72.3 \pm 19.5 \\
95.3 \pm 20.6\end{array}$ & $\begin{array}{r}- \\
8.2 \\
32.4 \\
119.1 \\
188.8\end{array}$ & $\begin{array}{l}1 \\
3 \\
3 \\
4 \\
4\end{array}$ & $\begin{array}{l}0 \\
3 \\
3 \\
3 \\
3\end{array}$ \\
\hline $\mathrm{LD}, 15 \mathrm{C}$ & $\begin{array}{r}0 \\
7 \\
14 \\
21 \\
28\end{array}$ & $\begin{array}{l}30.4 \pm 6.1 \\
30.8 \pm 6.4 \\
34.2 \pm 7.0 \\
42.0 \pm 9.8 \\
50.0 \pm 9.9\end{array}$ & $\begin{array}{r}- \\
1.3 \\
12.5 \\
38.2 \\
64.5\end{array}$ & $\begin{array}{l}1 \\
2 \\
3 \\
3 \\
4\end{array}$ & $\begin{array}{l}0 \\
0 \\
3 \\
3 \\
3\end{array}$ \\
\hline
\end{tabular}

"Three turions per treatment, cold treatment: 17 days at $0-4 \mathrm{C}$ in darkness.

b, c, d See footnotes of Table 1 .

The extraction procedure and bioassays were carried out as described in Weber and Noodén (1976).

Results-As shown diagrammatically in Fig. 1 , the germination of a $M$. verticillatum turion started with the reflexing of the turion leaves (leaf reflexing), followed by the elongation (progressing from the basal internodes) and curving of the stem (also see Fig. 2), and finally the development of roots at the basal nodes. While the order of events given above was generally as stated, there was much overlap of the stages, e.g., elongation began before all the turion leaves were reflexed. During axis elongation, some turions started to float, and by the time germination was completed, all turions were buoyant. Since stem elongation was found to be the most reliable indicator of germination, it was used most often as a measure of germination; however, parallel observations were made on leaf reflexing and root development.

Tarle 4. The effect of different light intensities on the clongation of abscised, cold-treated turions $\mathrm{s}^{\mathrm{a}}$

\begin{tabular}{|c|c|c|c|c|}
\hline \multirow[b]{2}{*}{ Treatment } & \multirow{2}{*}{$\begin{array}{l}\text { Light intensity } \\
\left(\mu \mathrm{E} \mathrm{nl}^{-2} \mathrm{sec}^{-1}\right)\end{array}$} & \multirow{2}{*}{$\begin{array}{c}\text { Time } \\
\text { (days) }\end{array}$} & \multicolumn{2}{|c|}{ Length } \\
\hline & & & $(\mathrm{mm})^{\mathrm{b}}$ & $(\%)^{c}$ \\
\hline $\mathrm{SD}, 15 \mathrm{C}$ & 200 & $\begin{array}{r}0 \\
14\end{array}$ & $\begin{array}{l}49.7 \pm 17.0 \\
89.0 \pm 25.2\end{array}$ & $\overline{79.1}$ \\
\hline \multirow[t]{3}{*}{$\mathrm{LD}, 20 \mathrm{C}$} & 200 & $\begin{array}{r}0 \\
14\end{array}$ & $\begin{array}{l}52.0 \pm 18 \\
84.7 \pm 18.6\end{array}$ & $\overline{62.9}$ \\
\hline & 100 & $\begin{array}{r}0 \\
14\end{array}$ & $\begin{array}{l}46.3 \pm 17.0 \\
82.3 \pm 18.1\end{array}$ & $\overline{77.7}$ \\
\hline & 50 & $\begin{array}{r}0 \\
14\end{array}$ & $\begin{array}{l}42.3 \pm 9.3 \\
83.0 \pm 16.1\end{array}$ & $\overline{96.2}$ \\
\hline
\end{tabular}

"Three turions per treatment, cold treatment: 60 days at $0-4 \mathrm{C}$ in darkness.

${ }^{b}, \mathrm{c}$ See footnotes in Table 1.
Environmental control-Photoperiod affected germination (outgrowth) of turions; however, the effect differed depending upon whether the turions had abscised and/or experienced a cold treatment. Most experiments were carried out at $15 \mathrm{C}$, which is near the maximum temperature at which turions are formed outdoors on rooted plants and therefore is not likely to break dormancy (Weber and Noodén, 1974a). Turions still attached to the plants elongated after a lag time of 1-1.5 wk when placed under long-days (LD, $16 \mathrm{hr}$ ) at $15 \mathrm{C}$, but not in short days (SD, $8 \mathrm{hr}$ ) (Table 1). Detachment of turions before they had abscised did not change their response to photoperiod. In contrast, those which were permitted to develop to natural
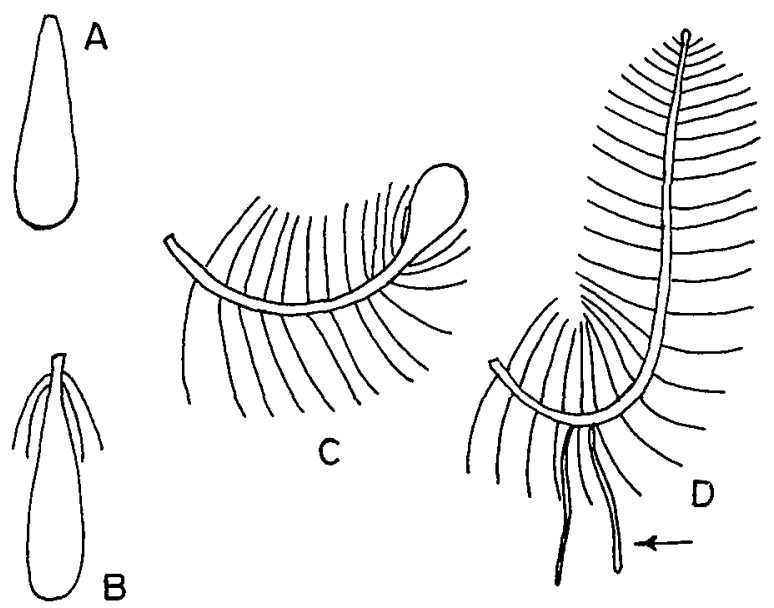

Fig. 1. Stages in the germination of turions. A. Leaves not reflexed (degree of reflexing: 1). B. Basal leaves just reflexing; axis may begin curving (degree of reflexing: 2). C. Leaves reflexing, axis curving; roots may appear (degree of reflexing: 3 ). D. Leaves reflexed, no turion character left, roots developing (arrow) (degree of reflexing: 4 ). 
TABLE 5. The elongation, degree of leaf reflexing, and root development of abscised, dormant turions which have been pre-treated with 7-11 SD at $15 C^{\mathrm{n}}$

\begin{tabular}{|c|c|c|c|c|c|}
\hline & \multirow{2}{*}{$\begin{array}{c}\text { Time } \\
\text { (days) }\end{array}$} & \multicolumn{2}{|c|}{ Length } & \multirow{2}{*}{$\begin{array}{l}\text { Degree of } \\
\text { refiexingd }\end{array}$} & \multirow{2}{*}{$\begin{array}{l}\text { No. of plants } \\
\text { with roots }\end{array}$} \\
\hline Treatment & & $(\mathrm{mm})^{b}$ & $(\%)^{\mathrm{e}}$ & & \\
\hline
\end{tabular}

Type A (leaves reflexed) ${ }^{\bullet}$

LD

$\begin{array}{rlc}0 & 31.2 \pm 4.0 & - \\ 21 & 31.5 \pm 4.3 & 1.0 \\ 36 & 32.0 \pm 3.2 & 2.6 \\ 0 & 29.6 \pm 8.2 & - \\ 21 & 34.3 \pm 11.1 & 15.9 \\ 36 & 48.3 \pm 21.7 & 63.2\end{array}$

$\begin{array}{ll}1.0 & 1 \\ 2.6 & 3 \\ & 3 \\ 5.9 & 1 \\ 63.2 & 3 \\ \end{array}$

$\begin{array}{ll}1 & 0 \\ 3 & 0 \\ 3 & 0 \\ 1 & 0 \\ 3 & 4 \\ 4 & 6\end{array}$

Type B (leaves not reflexed) ${ }^{\circ}$

$\begin{array}{rrrllll}\text { SD } & 0 & 27.2 \pm 3.8 & - & 1 & 0 \\ & 21 & 26.7 \pm 4.4 & -1.8 & 2 & 0 \\ \text { LD } & 36 & 27.0 \pm 4.7 & -0.7 & 2 & 0 \\ & 0 & 26.7 \pm 3.4 & - & 1 & 0 \\ & 21 & 26.7 \pm 3.6 & 0 & 3 & 0 & 6\end{array}$

${ }^{a}$ Six turions per treatment.

b. e, "See footnotes of Table 1.

e See text for explanation.

abscission (referred to subsequently as abscised, dormant turions) did not elongate readily in response to LD. One group of abscised, dormant turions was sub-divided and treated with $\mathrm{LD}$ or SD at 10,15 , or $20 \mathrm{C}$. In all cases, except LD at 20 $\mathrm{C}$, nearly all of these turions remained dormant for nearly 6 wk (Table 2); however, even under $\mathrm{LD}$ at $20 \mathrm{C}$, some remained dormant, which is the reason for the high standard deviation.

Cold-treated, abscised turions (collected in late winter, just after the ice had left the lake) elongated very rapidly (approximately 50\% increase in length in 1 wk) under both LD and SD at 15 C. A 17-day cold-treatment $(0-4 \mathrm{C}$ in a cold room) released the turions from dormancy; they elongated under both LD (50\% increase in length in $4 \mathrm{wk}$ ) and $\mathrm{SD}$ (50\% increase in $2.5 \mathrm{wk}$ ) (Table 3). When this cold-treatment was extended to 60 days, the outgrowth was even more rapid ( $50 \%$ increase in about 10 days, Table 4 ). In contrast, non-cold-treated turions elongated very slowly or not at all (Table 2). Eventually, turions showed signs of germination at $0-4 \mathrm{C}$ in a cold room much as they do in the field; however, outgrowth proceeded very slowly at this temperature. Partial cold treatment (16 days at $10 \mathrm{C}$ ) partially released dormancy when the turions were brought back to $15 \mathrm{C}$, but turions which received this treatment elongated only under LD conditions.

Following a full cold-treatment $(0-4 \mathrm{C})$, turions elongated more rapidly in $\mathrm{SD}$ than in $\mathrm{LD}$ (Table 3). Since light at higher intensities is known to inhibit stem elongation (see Sachs, 1965), the effect of light intensity on elongation was tested. Cold-treated turions grew faster under LD at light intensities of $50 \mu \mathrm{E} \mathrm{m} \mathrm{mec}^{-1}$ and $100 \mu \mathrm{E} \mathrm{m}^{-2} \mathrm{sec}^{-1}$ than at full light intensity (200

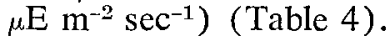

A curious differentiation into two dormancy classes was found among abscised, non-coldtreated turions stored for 7-11 SD at $15 \mathrm{C}$-those which started reflexing their leaves (type A) and those in which the leaves remained closed (type B). The response of these classes of turions to photoperiod differed (Table 5). Type A turions began to elongate under $\mathrm{LD}$ at $15 \mathrm{C}$ within 15 days, whereas type B turions did not. When the

TABLE 6. Effect of $G A_{3}$ on the elongation of pre-dormant (attached) turions, dormant turions, and coldtreated turions"

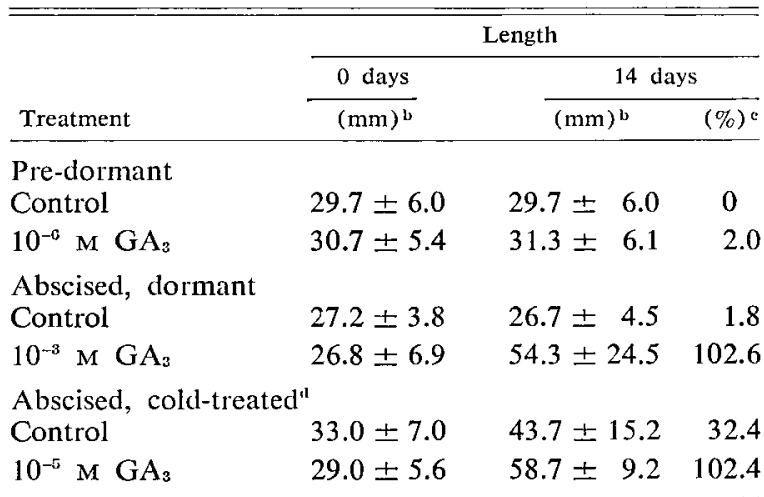

${ }^{a}$ Three turions per treatment; SD at $15 \mathrm{C}$.

b, c See footnotes of Table 1 .

'Pre-treatment: 0-4 C for 17 days. 


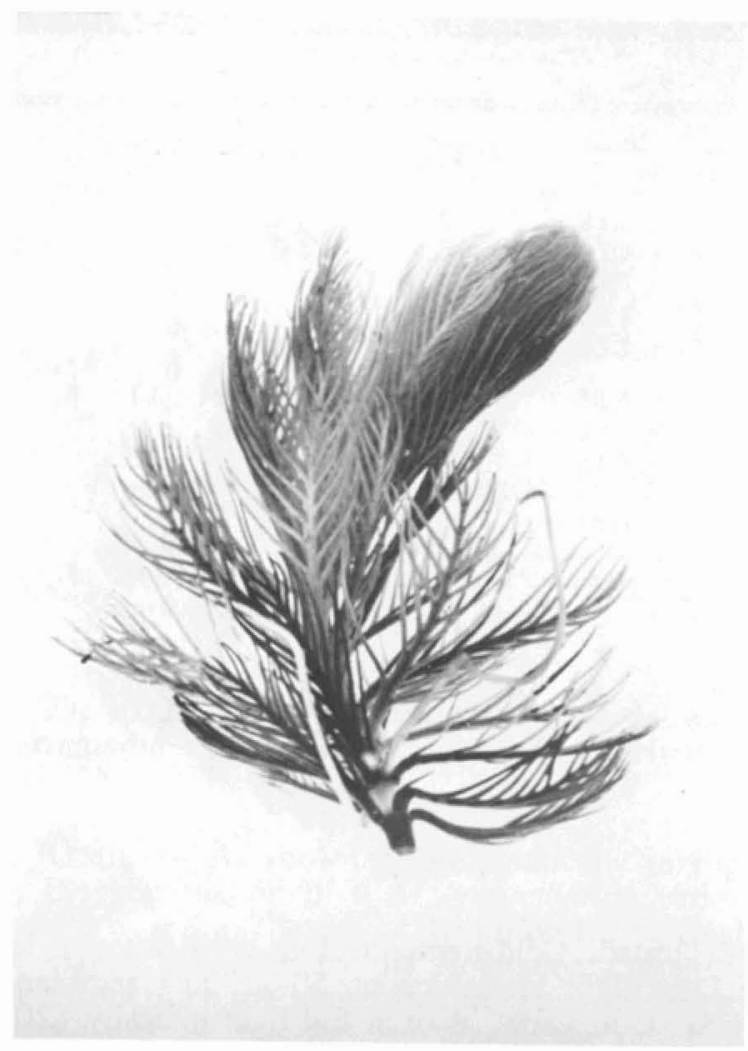

Fig. 2. Germinating turion of Myriophyllum verticillatum, about $3 \mathrm{~cm}$ long.

time at $15 \mathrm{C}$ in SD was extended to 54 days, type $\mathrm{B}$ turions elongated in response to $\mathrm{LD}$ at $15 \mathrm{C}$.

Since turion germination is marked by leaf reflexing and root formation, in addition to axis elongation (See Fig. 1), data were collected on these phenomena. Although leaf reflexing occurred first and root formation generally followed outgrowth, outgrowth did not necessarily follow leaf opening (see Tables 1,5 ). In addition, a few turions produced roots before their leaves reflexed. The leaves of type B turions did not reflex as much as the other classes in response to temperature and photoperiodic conditions (Table 5). Exposure to LD promoted root development (Tables 1,5). Finally, cold treatment at 0-4 C promoted both leaf reflexing and root development (Table 3).

Effects of applied growth regulators-The response of turions to $\mathrm{GA}_{3}$ varied greatly depending on whether they were abscised and/or cold-treated (Table 6). $\mathrm{GA}_{3}\left(10^{-6} \mathrm{M}\right.$ ) induced outgrowth in some attached turions in both SD and LD, causing a $25 \%$ increase in length in $3 \mathrm{wk}$ for some cases but not others, such as those in Table 6 . As the turions matured, they became less sensitive to exogenous $\mathrm{GA}_{3}$. Dormant turions are unaffected by $10^{-5} \mathrm{M} \mathrm{GA}_{3}$; however, $10^{-3} \mathrm{M} \mathrm{GA}_{3}$ did break dormancy in both LD and SD. After a 2-week cold-treatment, turion outgrowth again could be stimulated by $\mathrm{GA}_{3}$ at $10^{-5}$ and $10^{-6} \mathrm{M}$ in both $\mathrm{LD}$ and SD.

The cytokinins broke dormancy more effectively than any other growth regulators tested; however, the different cytokinins varied in their effectiveness. Kinetin and zeatin were not as active as BA, so BA was used in most experiments. Even dormant turions elongated in response to cytokinins after a lag of about 2 wk; both type A and type B turions responded similarly (Table 7). With or without cytokinins, the lag phase after a cold-treatment at $0-4 \mathrm{C}$ was less than 7 days. Unlike other dormancy-breaking treatments, BAinduced outgrowth slowed or even ceased by the fourth week of continuous treatment.

BA had an interesting effect on the gross morphology of the germinating turions; these turions produced none or only very short roots. In addition, large buds formed in the lower portion of the central axis, and the axis itself expanded in diameter. Cross sections showed that this thickening of the axis from about $1 \mathrm{~mm}$ in the control to

TABLE 7. Effect of cytokinins on the elongation of abscised, dormant and cold-treated turions $s^{\mathrm{n}}$

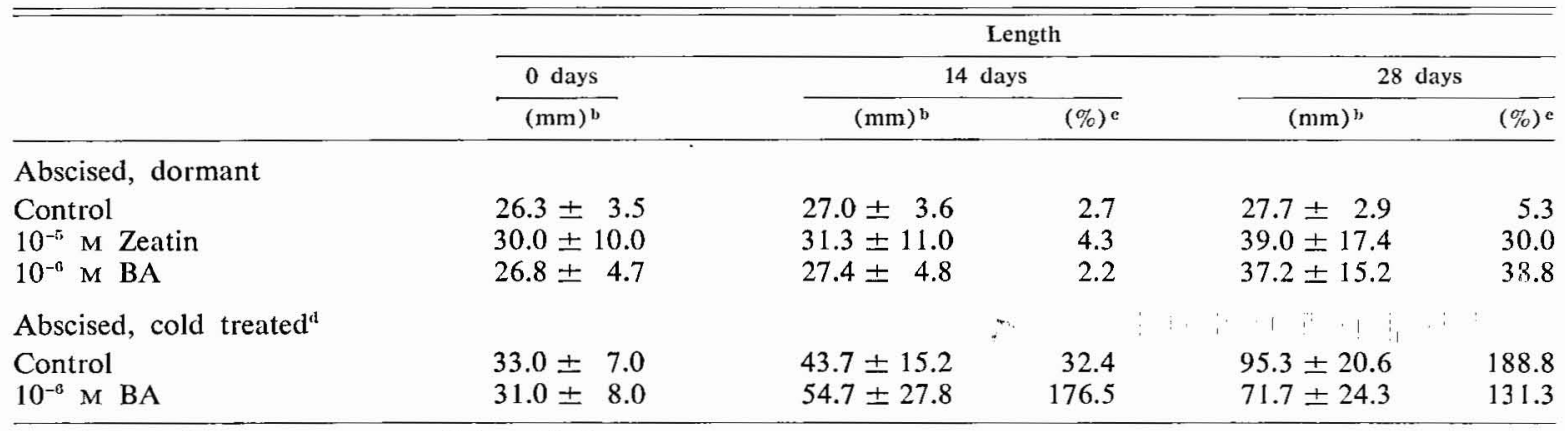

${ }^{\mathrm{a}}$ Three turions per treatment; SD at $15 \mathrm{C}$.

${ }^{b, ~ c}$ See footnotes for Table 1.

"Pre-treatment: $0-4 \mathrm{C}$ for 17. 
TABLE 8. Effect of high concentrations of IAA on the elongation of abscised, dormant turions ${ }^{x}$

\begin{tabular}{|c|c|c|c|c|c|}
\hline \multirow[b]{3}{*}{ Treatment } & \multicolumn{5}{|c|}{ Length } \\
\hline & \multirow{2}{*}{$\frac{0 \text { days }}{(\mathrm{mm})^{b}}$} & \multicolumn{2}{|c|}{7 days } & \multicolumn{2}{|c|}{14 days } \\
\hline & & $(\mathrm{mm})^{\mathrm{b}}$ & $(\%)^{\mathrm{c}}$ & $(\mathrm{mm})^{\mathrm{b}}$ & $(\%)^{\mathrm{c}}$ \\
\hline Control & $25.8 \pm 6.1$ & $27.0 \pm 6.2$ & 4.7 & $28.8 \pm 8.1$ & 11.6 \\
\hline $1.1 \times 10^{-4} \mathrm{M}$ & $23.2 \pm 6.5$ & $29.8 \pm 9.2$ & 28.4 & $33.3 \pm 9.7$ & 43.5 \\
\hline $2.8 \times 10^{-3} \mathrm{M}$ & $23.2 \pm 7.3$ & $26.2 \pm 5.0$ & 12.9 & $26.7 \pm 5.9$ & 15.1 \\
\hline
\end{tabular}

"Three turions per treatment; SD at $15 \mathrm{C}$.

ᄂ, c See footnotes for Table 1.

2-3 $\mathrm{mm}$ in treated turions was accompanied by an increase in the size of the internal air space.

IAA was relatively ineffective in promoting germination of turions. Up to $10^{-5} \mathrm{M}$, IAA had no detectable effect on abscised turions whether dormant or not. At herbicidal concentrations $(1.1 \times$ $10^{-4}$ and $\left.2.8 \times 10^{-3} \mathrm{M}\right)$, it definitely promoted outgrowth of dormant turions (Table 8), but the leaves were contorted and lighter green than the controls. Furthermore, growth soon ceased in the higher concentration. To determine whether penetration of IAA occurred at lower concentrations, turions were incubated in a carboxyl-labelled ${ }^{14} \mathrm{C}$ IAA $\left(6 \times 10^{-7} \mathrm{M}\right)$. After about $2 \mathrm{hr}$, the internal concentration of extractable ${ }^{14} \mathrm{C}$-IAA was approximately equal to that in the medium.

Ethephon, which apparently acts through breakdown to ethylene (Yang, 1969), promoted the outgrowth of dormant turions but only under 16hr photoperiods (Table 9). The tips of the leaves of all Ethephon-treated turions began turning brown by 23 days after the start of the treatment, an indication of toxic side effects.

The growth inhibitor, ABA, was applied to both attached and abscised turions; it inhibited outgrowth in all cases, especially before the turions received a cold-treatment (Table 10$)$. ABA $\left(10^{-5}\right.$ M) completely blocked the outgrowth of type A turions, whereas it only reduced the outgrowth of cold-treated turions. Just as ABA at $10^{-5}$ and $10^{-6}$

TABLE 9. Effect of Ethephon $\left(10^{-4} \mathrm{M}\right)$ on the elongation of abscised, dormant turions ${ }^{2}$

\begin{tabular}{lll}
\hline \hline & \multicolumn{2}{c}{ Length } \\
\cline { 2 - 3 } Treatment & $\frac{21 \text { days }}{(\mathrm{mm})^{\mathrm{b}}(\%)^{\mathrm{c}}}$ \\
\hline
\end{tabular}

\section{SD}

\begin{tabular}{lrrr} 
Control & $23.8 \pm 5.0$ & $24.3 \pm 4.8$ & 2.1 \\
Ethephon & $23.0 \pm 2.9$ & $22.8 \pm 3.2$ & -0.9 \\
L & & & \\
Control & $26.3 \pm 4.9$ & $23.7 \pm 1.2$ & 6.4 \\
Ethephon & $28.0 \pm 5.2$ & $32.3 \pm 6.4$ & 36.3 \\
\hline
\end{tabular}

\footnotetext{
"Three turions per treatment; $15 \mathrm{C}$.
}

b. c See footnotes for Table 1 .
M blocked outgrowth of cold-treated turions, it abolished outgrowth induced by BA $\left(10^{-6} \mathrm{M}\right)$ in dormant turions (Table 11). However, ABA did not block the effect of BA on cold-treated turions. ABA retarded $\mathrm{GA}_{3}$-stimulated outgrowth of coldtreated turions.

Leaf reflexing, stem curvature and elongation, and root formation in turions treated with growth promoters followed the typical sequence described earlier. Where a treatment accelerated outgrowth, leaf reflexing, stem curvature, and root formation were correspondingly accelerated. The only exception was the inhibition of root development by the cytokinin treatments.

Endogenous growth regulators-The level of acid-ether-extractable inhibitors in all turions was less than $1 \mu \mathrm{g}$ ABA equivalents per $50 \mathrm{~g}$ fresh weight when measured by the oat coleoptile straight-growth test (Table 12); the principal zone of inhibition was at $R_{\mathrm{f}}$ 0.6-0.8 on chromatograms developed in BPAW solvent. Attached and

TABLE 10. The effect of $A B A\left(10^{-5} \mathrm{M}\right)$ on the elongation of attached, abscised dormant (Type $A$ and $B$ ) and cold-treated turions ${ }^{\mathrm{a}}$

\begin{tabular}{|c|c|c|c|}
\hline \multirow[b]{3}{*}{ Treatment } & \multicolumn{3}{|c|}{ Length } \\
\hline & \multirow{2}{*}{$\frac{0 \text { days }}{(\mathrm{mm})^{b}}$} & \multicolumn{2}{|c|}{28 days } \\
\hline & & $(\mathrm{mm})^{\mathrm{l}}$ & $(\%)^{\mathrm{c}}$ \\
\hline \multicolumn{4}{|l|}{ Attached } \\
\hline Control & $34.3 \pm 6.6$ & $40.3 \pm 16.3$ & 17.5 \\
\hline $\mathrm{ABA}$ & $29.7 \pm 3.5$ & $29.5 \pm 2.4$ & -0.7 \\
\hline \multicolumn{4}{|c|}{ Abscised, dormant Type $A^{d}$} \\
\hline Control & $29.6 \pm 8.2$ & $42.8 \pm 18.3$ & 44.6 \\
\hline $\mathrm{ABA}$ & $31.8 \pm 4.2$ & $32.2 \pm 4.2$ & 1.3 \\
\hline \multicolumn{4}{|c|}{ Abscised, dormant Type $\mathrm{B}^{\mathrm{d}}$} \\
\hline Control & $26.7 \pm 3.4$ & $26.7 \pm 3.6$ & 0 \\
\hline ABA & $25.8 \pm 1.7$ & $25.8 \pm 1.5$ & 0 \\
\hline \multicolumn{4}{|c|}{ Abscised, cold-treated ${ }^{\circ}$} \\
\hline Control & $30.4 \pm 6.1$ & $50.0 \pm 9.9$ & 64.5 \\
\hline ABA & $33.5 \pm 6.5$ & $45.2 \pm 13.4$ & 34.9 \\
\hline
\end{tabular}



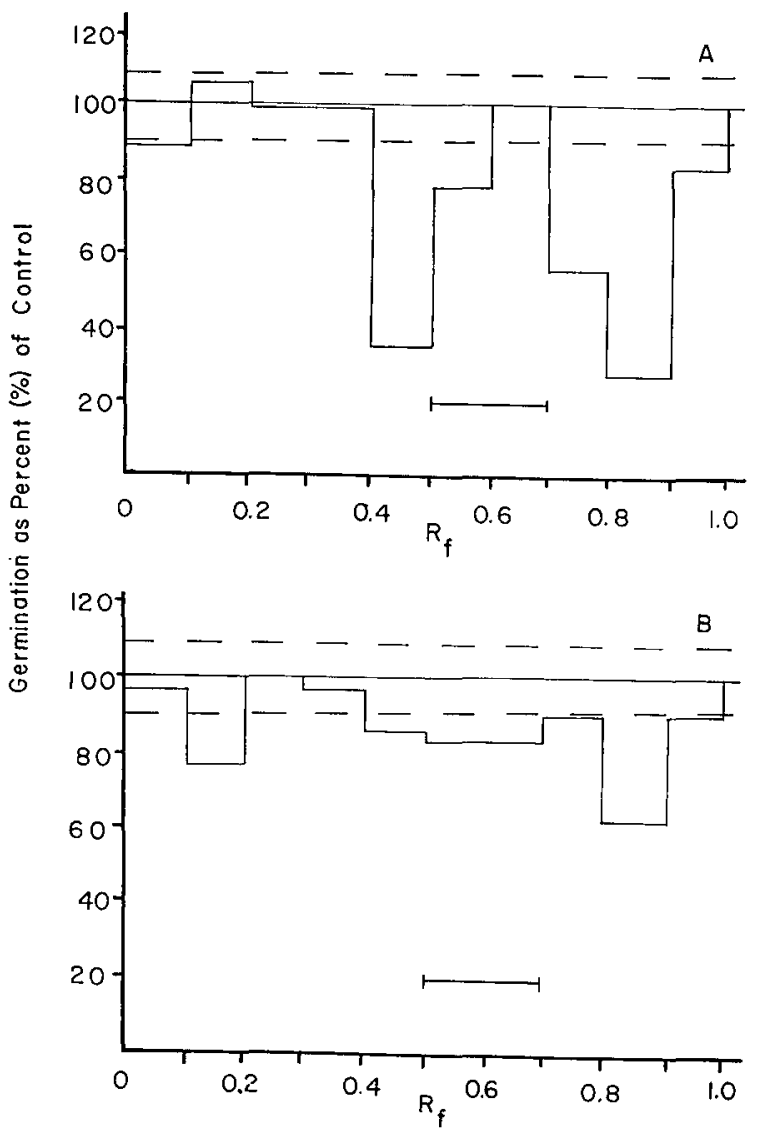

Fig. 3. Lettuce seed germination bioassay for inhibitors in the acidic-ether fraction of extracts of turions. A. Dormant turions collected on 28 October 1970 (35 $\mathrm{g}$ fresh-weight equivalent). B. Germinating turions collected on 8 April 1971 (50 g fresh-weight equivalent). Paper chromatogram developed in 2-propanol/ $\mathrm{NH}_{4} \mathrm{OH} /$ $\mathrm{H}_{2} \mathrm{O}(10: 1: 1, \mathrm{v} / \mathrm{v})$. The bar indicates the $\mathrm{R}_{\mathrm{f}}$ zone to which synthetic $\pm \mathrm{ABA}$ and $\mathrm{ABA}$ extracted from avocado migrate.

abscised dormant turions had essentially the same level of ABA-like inhibitor activity. During germination, however, there was a rise in the level of ABA-like activity from 0.4 to $0.8 \mu \mathrm{g}$ ABA equivalents per $50 \mathrm{~g}$ fresh weight. The lettuce seed germination bioassay gave somewhat different results in that the inhibitory activity in the ABA zone showed little or no change; however, inhibitory activity in zones before and after $\mathrm{ABA}$ showed a marked decrease after germination (Fig. $3)$.

The levels of gibberellins and auxins were too low to be measured reliably with the methods used; however, the levels of cytokinin-like activity did change during dormancy and germination. Although no cytokinin activity could be detected in either the acidic or basic ether phases, cytokinin activity was found in the butanol-soluble fraction (Table 13).
TABLE 11. Effect of $A B A\left(10^{-0} \mathrm{M}\right)$ on $B A\left(10^{-\mathrm{a}} \mathrm{M}\right)$ and $G A_{3}\left(10^{-6} \mathrm{M}\right)$ induced elongation of abscised, dormant, and cold-treated turions ${ }^{\mathrm{n}}$

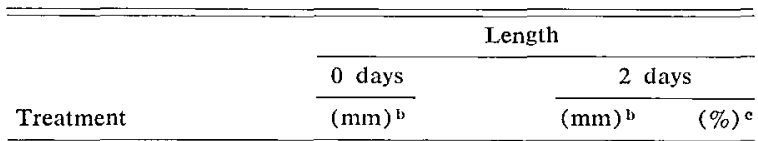

Abscised, dormant

\begin{tabular}{|c|c|c|c|}
\hline BA & $26.8 \pm 4.7$ & $31.0 \pm$ & 5.7 \\
\hline $\mathrm{ABA}$ & $26.7 \pm 6.1$ & $27.7 \pm$ & 6.1 \\
\hline $\mathrm{BA}+\mathrm{ABA}$ & $25.6 \pm 4.5$ & $26.0 \pm$ & 3.8 \\
\hline
\end{tabular}

Abscised, cold-treated ${ }^{\mathrm{u}}$

$\begin{array}{lccr}\mathrm{BA} & 31.0 \pm 8.0 & 68.3 \pm 26.1 & 120.3 \\ \mathrm{ABA} & 33.7 \pm 1.1 & 36.7 \pm 1.6 & 8.9 \\ \mathrm{BA}+\mathrm{ABA} & 29.7 \pm 8.0 & 77.7 \pm 46.3 & 161.6 \\ \mathrm{GA}_{3} & 30.7 \pm 5.9 & 73.0 \pm 14.9 & 137.8 \\ \mathrm{GA}_{3}+\mathrm{ABA} & 31.7 \pm 8.1 & 51.7 \pm 6.8 & 63.1\end{array}$

"Three turions per treatment; SD at $15 \mathrm{C}$.

b. "See footnotes for Table 1.

"Pre-treatment: 0-4 C for 17 days.

Discussion-Environmental control-Pre-dormant turions, still attached the parent plant, are maintained in the dormant state by photoperiod and possibly also temperature. Turions which have abscised but have not had a dormancybreaking treatment, e.g., cold temperatures, are in a deeper state of dormancy. The intensity of this dormancy is apparently variable, because under certain favorable conditions some of the turions germinated, albeit slowly, without being cold-treated as indicated by the large standard deviation in some cases. Cold treatment at $0-4$ $\mathrm{C}$ produces the most complete release from dormancy, and if continued for about one month, the turions begin to germinate even in darkness at 0-4 C (conditions which may resemble those at the bottom of a lake in midwinter). The effect of cold temperatures compares well with the observation that turions begin germinating before the ice has begun to leave the lake (Weber and Noodén, 1974a).

Hormonal control-From the work of many researchers, it has become evident that dormancy is probably controlled by more than one growth regulator (Phillips and Wareing, 1958, 1959; Esashi and Leopold, 1969; Wareing and Saunders, 1971; Lenton, Perry, and Saunders, 1972; Hashimoto, Hasegawa, and Kawarada, 1972). However, the classes of hormones which are most frequently found to be important are the gibberellins and the acidic inhibitors, particularly abscisic acid. There is also some evidence for the involvement of cytokinins (Chvojka, Trávníček and Zakouřilová, 1962; Domanski and Kozlowski, 1968; Hewett and Wareing, 1973).

Cytokinins, especially BA, effectively induced 
TABLE 12. Level of ABA-like inhibitory activity in the acidic-ether fraction of extracts of turions ${ }^{\text {it }}$

\begin{tabular}{lcc}
\hline & $\begin{array}{c}\mu \mathrm{g} \text { ABA equivalents } \\
\text { per } 50 \mathrm{~g} \text { fr wt }\end{array}$ & $\begin{array}{c}\text { Date } \\
\text { collected }\end{array}$ \\
\hline $\begin{array}{l}\text { Attached turions } \\
\begin{array}{l}\text { Abscised, dormant } \\
\text { turions }\end{array}\end{array}$ & 0.38 & 27 October 1972 \\
Germinating turions & 0.81 & 27 October 1972 \\
\end{tabular}

"Thin-layer chromatogram developed in BPAW (1butanol/1-propanol/ $\mathrm{NH}_{4} \mathrm{OH} / \mathrm{H}_{2} \mathrm{O}, 2: 6: 1: 2, \mathrm{v} / \mathrm{v}$ ), activity in the oat coleoptile straight growth test at $R_{\mathrm{f}} 0.6$ to 0.8 (the region where $\mathrm{ABA}$ migrates).

outgrowth in turions of $M$. verticillatum in all stages of dormancy; however, development of cytokinin-treated turions differed quite substantially from control turions. Kinetin has a similar effect on turions of Hydrocharis morsus-ranae (Kummerow, 1958). The endogenous cytokinin activity in $M$. verticillatum rises to a peak in abscised, dormant turions and then drops during germination, similar to the pattern reported in dormant seeds (Van Staden, Webb and Wareing, 1972) and buds (Tucker and Mansfield, 1972; Englebrecht and Bielinska-Czarnecka, 1972).

The response of $M$. verticillatum turions to $\mathrm{GA}_{3}$ is similar to that noted by Leike (1967) and Hatch and Walker (1969) for terminal buds of various woody plants where "sensitivity" to exogenous $\mathrm{GA}_{3}$ varied with dormancy, being least responsive during deep dormancy. It is not clear whether these changes in the responsiveness to exogenous $\mathrm{GA}_{3}$ are changes in permeability or actual changes in sensitivity. The fact that $\mathrm{GA}_{3}$, albeit at high concentrations, is able to induce apparently normal outgrowth in dormant $M$. verticillatum turions suggests that a gibberellin deficiency may play some role in maintaining dormancy.

Ethylene promotes stem elongation in Callitriche platycarpa Kutz. (Musgrave, Jackson and Ling, 1972) and rachis elongation in Regnillidium diphyllum Lindman (Musgrave and Walters, 1974), both aquatic vascular plants. However, we found no evidence that it is important in turion germination. Likewise, our results suggest that auxins are not important in controlling dormancy in these turions.

The germination of turions coincides with a decrease in the levels of inhibitory substances which are apparently unlike $\mathrm{ABA}$, while the level of ABA-like material increases somewhat. Lenton et al. (1971) have also reported no change in ABA level during bud break in three tree species.

The dormancy and germination of turions of $M$. verticillatum are controlled by temperature and photoperiod. Both growth inhibitors (ABA and other acid ether-soluble inhibitors) and promoters (cytokinins and possibly gibberellin) ap-
TABLE 13. Cytokinin activity in the butanol fraction of extracts of turions

\begin{tabular}{|c|c|c|c|}
\hline Stage & $\%$ of control ${ }^{13}$ & $\begin{array}{l}\text { Zeatin } \\
\text { equivalents } \\
(\mu \mathrm{g})\end{array}$ & $\begin{array}{c}\text { Date } \\
\text { collected }\end{array}$ \\
\hline $\begin{array}{l}\text { Attached, devel- } \\
\text { oping }\end{array}$ & $156.1 \pm 10.1$ & 3.0 & 9 October \\
\hline Attached, mature & $127.0 \pm 9.6$ & 0.4 & 27 October \\
\hline $\begin{array}{l}\text { Abscised, } \\
\text { dormant }\end{array}$ & $156.3 \pm 0.9$ & 3.0 & 27 October \\
\hline $\begin{array}{l}\text { Germinating (afte } \\
\text { cold-treatment) }\end{array}$ & $125.3 \pm 7.6$ & 0.4 & 16 January \\
\hline
\end{tabular}

"Chlorophyll retention in detached oat leaves. $50 \mathrm{~g}$ fresh-weight equivalent of turion extract.

'Water-treated control assumed as $100 \%$.

pear to control dormancy and outgrowth of these turions.

\section{LITERATURE CITED}

Chvojka, L., M. TrávníčEk, and M. ZakouŘilová. 1962. The influence of stimulating doses of 6benzylaminopurine on awakening apple buds and on their consumption of oxygen. Biol. Plant. (Praha) 4: 203-206.

Domanski, R., AND T. T. Kozlowski. 1968. Variations in kinetin-like activity in buds of Betula and Populus during release from dormancy. Can. J. Bot. 46: 397-403.

Engelbrecht, L., and M. Bielinska-CZarnecka. 1972. Increase of cytokinin activity in potato tubers near the end of dormancy. Biochem. Biophys. Pflanzen. 163: 499-504.

Esashi, Y., AND A. C. Leopold. 1969. Regulation of the onset of dormancy in tubers of Begonia evansiana. Plant Physiol. 44: 1200-1202.

Hashimoto, T., K. Hasegawa, and A. Kawarada. 1972. Batatasins: New dormancy-inducing substances of yam bulbils. Planta (Berl.) 108: 369374.

Hatch, A. H., and D. R. Walker. 1969. Rest intensity of dormant peach and apricot leaf buds as influenced by temperature, cold hardiness and respiration. J. Am. Soc. Hort. Sci. 94: 304-307.

Hewett, E. W., and P. F. Wareing. 1973. Cytokinins in Populus $\times$ robusta: Changes during chilling and bud burst. Physiol. Plant, 28: 393-399.

JACOBS, D. L. 1947. An ecological life-history of Spirodela polyrhiza (greater duckweed) with emphasis on the turion phase. Ecol. Monogr. 17: 437469.

Kummerow, A. 1958. Beitrage zur Kenntnis der Ruheperiode von Winterknospen und Samen. Beitr. Biol. Pflanz. 34: 293-314.

LACOR, M. A. M. 1969. On the influence of gibberellic acid and kinetin on the germination of turions of Spirodela polyrhiza (L.) Schleiden. Acta. Bot. Neerl. 18: 550-557.

LEIKE, H. 1967. Wirkung von Gibberellinsäure und Kinetin auf ruhende Knospen verschiedener Gehölze. Flora (Jena), Abt. A 158: 351-362.

Lenton, J. R., V. M. Perry, and P. F. SAUnders. 1972. Endogenous abscisic acid in relation to photoperiodically induced bud dormancy. Planta (Berl.) 106: 13-22. 
Musgrave, A., M. B. JaCkson, AND E. Ling. 1972. Callitriche stem elongation is controlled by ethylene and gibberellin. Nat. New Biol. 238: 93-96.

Musgrave, A. AND J. Walters. 1974. Ethylene and buoyance control rachis elongation of the semiaquatic fern Regnillidium diphyllum. Planta (Berl.) 121: $51-56$.

PERRY, T. O. 1968. Dormancy, turion formation, and germination by different clones of Spirodela polyrhiza. Plant Physiol. 43: 1866-1869.

Phillips, I. D. J., AND P. F. Wareing. 1958. Studies in dormancy of sycamore. I. Seasonal changes in the growth-substance content of the shoot. J. Exp. Bot. 9: 350-364.

Phillips, I. D. J., and P. F. Wareing. 1959. Studies in dormancy of sycamore. II. The effect of daylength on the natural growth-inhibitor content of the shoot. J. Exp. Bot. 10: 504-514.

Pieterse, A. H., P. R. Bhalla, and P. S. Sabharwal. 1871. Endogenous gibberellins in floating plants and turions of Wolffiella floridana. Physiol. Plant. 24: $512-516$

SACHS, R. M. 1965. Stem elongation. Annu. Rev. Plant. Physiol. 16: 73-96.

Terras, J. A. 1900. Notes on the germination of the winter buds of Hydrocharis morsus-ranae. Trans. Proc. Bot. Soc. Edinb. 21: 318-329.

Tucker, D. J., ANd T. A. Mansfield. 1972. Effects of light quality on apical dominance in Xanthium strumarium and the associated changes in endogenous levels of abscisic acid and cytokinins. Planta (Berl.) 102: 140-151.

Van Staden, J., D. P. Webb, and P. F. Wareing. 1972. The effect of stratification of endogenous cytokinin levels in seeds of Acer saccharum. Planta (Berl.) 104: $110-114$

VEGIS, A. 1932. Über das Frühtreiben der Winterknospen von Hydrocharis morsus-ranae $\mathrm{L}$. durch Hochtemperierte Wasserbäder. Jarb. Wiss. Bot. 75: $726-770$.

. 1955. Über den Einfluss der Temperatur und der Täglich Licht-Dunkel-Periode auf die Bildung der Ruheknospen zugleich ein Beitruge zur Entstehung der Ruhezustandes. Symb. Bot. Ups. 14: 1175 .

Wareing, P. F., and P. F. Saunders. 1971. Hormones and dormancy. Annu. Rev. Plant Physiol. 22: 261288 .

WEBER, J. A. 1972. The importance of turions in the propagation of Myriophyllum exalbescens (Haloragidaceae) in Douglas Lake, Michigan. Mich. Bot. 11: 115-121.

, AND L. D. Noodén. 1972. Regulation of dormancy and germination of turions of Myriophyllum verticillatum L. Amer. J. Bot. 59(suppl.): 658 .

— AND 1974a. Turion formation and germination in Myriophyllum verticillatum: Phenology and its interpretation. Mich. Bot. 13: 151-158. - AND —. 1974b. Environmental and hor monal control of turion germination in Myriop/lyllum verticillatum L. Plant Physiol. 54(suppl.): 7. , AND —. 1976. Environmental and hormonal control of turion formation in Myriophyllum verticillatum. Plant Cell Physiol. 17: In press.

YANG, C. F. 1969. Ethylene evolution from 2-chloroethylphosphonic acid. Plant Physiol. 44: 12031204. 